\title{
Activated PTT/Standard Ratio Measurement
}

National Cancer Institute

\section{Source}

National Cancer Institute. Activated PTT/Standard Ratio Measurement. NCI Thesaurus. Code $C 98862$.

The determination of the ratio of a subject's partial thromboplastin time to a standard or control partial thromboplastin time. The measurement may be expressed as a ratio or percentage. 